\title{
Fire and Gas Barrier Properties of Poly(styrene-co-acrylonitrile) Nanocomposites Using Polycaprolactone/Clay Nanohybrid Based-Masterbatch
}

\author{
S. Benali, ${ }^{1}$ A. Olivier, ${ }^{1}$ P. Brocorens, ${ }^{2}$ L. Bonnaud, ${ }^{1,3}$ M. Alexandre, ${ }^{1,3}$ S. Bourbigot, ${ }^{4}$ \\ E. Espuche, ${ }^{5}$ F. Gouanve, ${ }^{5}$ R. Lazzaroni, ${ }^{2,3}$ and Ph. Dubois ${ }^{1,3}$ \\ ${ }^{1}$ Centre d'Innovation et de Recherche en Matériaux Polymères CIRMAP, Service des Matériaux Polymères et Composites, \\ Université de Mons-Hainaut, Académie Universitaire Wallonie-Bruxelles, Place du Parc 20, 7000 Mons, Belgium \\ ${ }^{2}$ Centre d'Innovation et de Recherche en Matériaux Polymères CIRMAP, Chimie des Matériaux Nouveaux, \\ Université de Mons-Hainaut, Académie Universitaire Wallonie-Bruxelles, Avenue N. Copernic 1, 7000 Mons, Belgium \\ ${ }^{3}$ Materia Nova asbl, Parc Initialis, Avenue N. Copernic number 1, 7000 Mons, Belgium \\ ${ }^{4}$ Laboratoire des Procédés d'Elaboration de Revêtements Fonctionnels, UMR/CNRS 8008, ENSCL, BP 90108, \\ 59652 Villeuneuve d'Ascq Cedex, France \\ ${ }^{5}$ Laboratoire des Matériaux Polymères et des Biomatériaux, UMR5223, Université Claude Bernard Lyon I, Bât ISTIL, \\ 15 Boulevard d A. Latarjet, 69622 Villeurbanne Cedex, France
}

Correspondence should be addressed to S. Benali, samira.benali@umh.ac.be

Received 21 May 2008; Revised 22 October 2008; Accepted 28 December 2008

Recommended by Susmita Bose

Exfoliated nanocomposites are prepared by dispersion of poly( $\varepsilon$-caprolactone) (PCL) grafted montmorillonite nanohybrids used as masterbatches in poly(styrene-co-acrylonitrile) (SAN). The PCL-grafted clay nanohybrids with high inorganic content are synthesized by in situ intercalative ring-opening polymerization of $\varepsilon$-caprolactone between silicate layers organomodified by alkylammonium cations bearing two hydroxyl functions. The polymerization is initiated by tin alcoholate species derived from the exchange reaction of tin(II) bis(2-ethylhexanoate) with the hydroxyl groups borne by the ammonium cations that organomodified the clay. These highly filled PCL nanocomposites (25 wt\% in inorganics) are dispersed as masterbatches in commercial poly(styrene-co-acrylonitrile) by melt blending. SAN-based nanocomposites containing 3 wt $\%$ of inorganics are accordingly prepared. The direct blend of SAN/organomodified clay is also prepared for sake of comparison. The clay dispersion is characterized by wide-angle X-ray diffraction (WAXD), atomic force microscopy (AFM), and solid state NMR spectroscopy measurements. The thermal properties are studied by thermogravimetric analysis. The flame retardancy and gas barrier resistance properties of nanocomposites are discussed both as a function of the clay dispersion and of the matrix/clay interaction.

Copyright () 2008 S. Benali et al. This is an open access article distributed under the Creative Commons Attribution License, which permits unrestricted use, distribution, and reproduction in any medium, provided the original work is properly cited.

\section{Introduction}

The research concerning polymer nanocomposites based on organolayered silicates [1-6] highlighted the interest of such clays not only for increasing the stiffness [4] of these materials, but also for enhancing other properties of the polymers such as thermal $[5,7-9]$, flame retardancy $[5,10]$ or gas barrier resistance properties $[11,12]$.

The possibility of reaching a large enhancement of polymer properties lies in the obtention of a high level of nanoparticle dissociation for an efficient separation of the silicate layers [1]. However, the use of classical processes for nanocomposite preparation (in situ intercalative polymerization or melt intercalation/delamination) is often insufficient to reach a homogeneous dispersion of these nanoparticles $[1,6]$.

Recently, a new two-step route to polymer/layered silicate nanocomposites characterized by a large extent of nanoplatelet delamination has been investigated [1316]. This efficient process, that is, the "poly( $\varepsilon$-caprolactone) (PCL)/clay nanohybrid masterbatch" technique, consists in combining a "grafting-from" intercalative polymerization followed by a melt delamination process. In the first step, an organomodified clay is prepared by ion exchange 
of sodium cations naturally present in montmorillonite (MMT) with an adequate amount of hydroxylated alkylammonium cations. Then, the silicate layers are delaminated by catalyzed ring-opening polymerization of $\mathcal{\varepsilon}$-caprolactone directly initiated from this adequately organomodified filler surface. And finally, the resulting polyester-grafted organoclay nanohybrids are used as masterbatches and are dispersed in commercial polymeric matrices by melt blending. This technique has already successfully led to a large improvement of clay dispersion within the PCL matrix [17] and a chlorinated polyethylene matrix $[15,16]$. In each case, typical properties of nanocomposites are studied both as a function of the clay dispersion and of the matrix/clay interactions.

Poly(styrene-co-acrylonitrile) (SAN) exhibits several interesting properties such as good mechanical and chemical resistance, optical transparency, and ease of processing. SAN is widely used in many applications in the household and sanitary sectors, for packaging cosmetic products as well as for electronic and office items. A number of studies on nanocomposites based on an SAN matrix have been published. These studies have been mainly focused on the organomodified clay effect $[8,10,18,19]$, acrylonitrile (AN) content effect [19-21], or the use of compatibilizing agent like PCL $[22,23]$ introduced by melt blending. Whatever the techniques used in these different works, only intercalated structures were evidenced by both WAXD and TEM analysis and thermal and flame retardancy properties have more or less been improved as a function of parameters studied. However, as expected from the general trends in nanocomposites properties $[1,6]$, these results should be enhanced by clay dispersion improvement.

So, the present work focuses on the PCL/clay nanohybrid masterbatch approach with SAN as the diluting matrix, in order to prepare new materials with an exfoliated nanostructure. Indeed, the miscibility between SAN and PCL $[22,23]$ allows to use PCL as a compatibilizer agent between SAN and MMT. Our study is part of a larger effort, which aims at developing SAN foams. So, it is worth rating that the present work does not aim first at improving the mechanical properties of SAN nanocomposites but rather at studying the relationships between the clay dispersion and the flame retardancy or barrier gas resistance properties. In order to highlight the interest of the PCL/clay nanohybrid masterbatch technique, a comparison has been carried out with just a melt intercalated SAN/organomodified clay.

\section{Experimental Part}

2.1. Materials. $\varepsilon$-caprolactone (CL, Fluka) was dried over $\mathrm{CaH}_{2}$ and distilled under reduced pressure prior to use. Tin (II) bis(2-ethylhexanoate), also known as tin(octoate) $\left(\mathrm{Sn}(\mathrm{Oct})_{2}\right)$, was purchased from Fluka (Switzerland), diluted with dried toluene, and stored under nitrogen atmosphere.

Commercial SAN, Luran $358 \mathrm{~N}$ (with $75 \mathrm{wt} \%$ of styrene) was supplied by BASF (Belgium). The SAN was systematically further stabilized by $0.05 \mathrm{wt} \%$ of Irganox MD1024 supplied by CIBA (Switzerland). CAPA 2402, a PCL oligomer
$\left(\mathrm{Mn}=4000 \mathrm{~g} \cdot \mathrm{mol}^{-1}\right)$ was obtained from Solvay Interox (UK). Cloisite 30B (CL30B), a montmorillonite organomodified by $23.4 \mathrm{wt} \%$ of methyl bis(2-hydroxyethyl)tallowalkyl ammonium cations was supplied by Southern Clay Products (Texas, USA).

2.2. Characterization. Thermogravimetric analysis (TGA) was performed at a heating rate of $20^{\circ} \mathrm{C} / \mathrm{min}$ from room temperature to $800^{\circ} \mathrm{C}$ by using an Hi-Res TGA 2950 device from TA Instruments (Del, NY, USA). Thermodegradation was determined on approximately $15 \mathrm{mg}$ samples with platinum sample pan in a $74 \mathrm{~cm}^{3} / \mathrm{min}$ helium flow. Thermooxidation was determined in the same way in a $69 \mathrm{~cm}^{3} / \mathrm{min}$ air flow.

The morphology of the nanocomposites has been analyzed by wide-angle X-ray diffraction (WAXD) and atomic force microscopy (AFM). WAXD patterns were recorded between $1.65^{\circ}$ and $30^{\circ}$ (by steps of $0.04^{\circ}$ ) with a Siemens D5000 diffractometer (Germany) operating with $\mathrm{CuK}_{\alpha}$ radiation $(\lambda=1.5406 \AA)$. For recording AFM images, the samples were cryomicrotomed at $-100^{\circ} \mathrm{C}$ by an Ultracut FC4E microtome from Reichert-Jung (Austria). A truncated pyramid is cut in the sample. Ultrathin sections of the pyramid are removed, while the $\sim 1 \times 1.5 \mathrm{~mm}^{2}$ top surface of the pyramid is imaged with AFM. The AFM images were recorded in tapping mode (TM) with a Nanoscope IIIa microscope from Veeco Instruments (USA). Both height and phase images of $512 \times 512$ data points were recorded in ambient atmosphere, at room temperature, using silicon probes with a spring constant of $24-52 \mathrm{~N} / \mathrm{m}$, a resonance frequency in the $264-339 \mathrm{kHz}$ range, and a typical radius of curvature of $10-15 \mathrm{~nm}$. The selected AFM images are representative of the morphology of the whole sample, as based on the analysis of a large number of materials sections. NMR spectroscopy measurements were conducted using a Bruker Avance 400 spectrometer (Germany) operating at 9.4 T. Proton spectra at $400 \mathrm{MHz}$ were obtained using a $5-\mathrm{mm}$ low proton-background probe.

It is known that the absorption of paramagnetic oxygen into aromatic polymers causes a major shortening of $\mathrm{T}_{1}{ }^{\mathrm{H}}$ (proton longitudinal relaxation time) [9]. Deoxygenated [9] granular samples were prepared by pumping in high vacuum for 2 hours at $50^{\circ} \mathrm{C}$ in $5 \mathrm{~mm}$ glass tubes followed by a sealing of the tubes. $\mathrm{T}_{1}{ }^{\mathrm{H}}$ recovery curves were then measured using the saturation-recovery sequence with direct proton observation. As a semiempirical approach to analysis, these saturation-recovery curves were fit to a twoexponential equation according to (1)

$$
M(t)=M_{0 \mathrm{~s}}\left(1-e^{-t / \mathrm{T}_{1 \mathrm{~s}}{ }^{\mathrm{H}}}\right)+M_{01}\left(1-e^{-t / \mathrm{T}_{11}{ }^{\mathrm{H}}}\right),
$$

where $M(t)$ is the magnetization at time $t, M_{0 \mathrm{~s}}$ and $M_{01}$ are the magnetizations of the short and long components, respectively, and $\mathrm{T}_{1 s}{ }^{\mathrm{H}}$ and $\mathrm{T}_{11}{ }^{\mathrm{H}}$ are the proton longitudinal relaxation times of the short and long components, respectively.

Qualitative fire tests consist of burning two bar specimens shaped in accordance to ASTM D 256 norm at the same time. A Fire Testing Technology (FTT, UK) mass loss calorimeter was used to carry out measurements 
on samples following the procedure defined in ASTM E 906. The equipment is identical to that used in oxygen consumption cone calorimetry (ASTM E-1354-90), except that a thermopile in the chimney is used to obtain the heat release rate (HRR) rather than employing the oxygen consumption principle. Mass loss readings are performed simultaneously by ASTM E-1354 and serve as a benchmark of the heat release rate values obtained in this manner. Our procedure involved exposing specimens measuring $100 \times$ $100 \times 3 \mathrm{~mm}^{3}$ in horizontal orientation. An external heat flux of $35 \mathrm{~kW} / \mathrm{m}^{2}$ with a cone shaped heater was used for running the experiments. This flux corresponds to a common heat flux in a mild fire scenario [24-27]. When measured at $35 \mathrm{~kW} / \mathrm{m}^{2}$, HRR is reproducible to within $+/-10 \%$. The cone data reported in this paper are the average of three replicated experiments.

Gas permeation experiments were carried out for $\mathrm{He}$, $\mathrm{O}_{2}$, and $\mathrm{CO}_{2}$ at $20^{\circ} \mathrm{C}$ under an upstream pressure equal to 3 bars. The permeation cell consisted of two compartments separated by the studied membrane. The pressure variations in the downstream compartment were measured as a function of time. The permeability coefficient $P$, expressed in barrer units, was calculated from the slope of the straight line in the steady state. The permeability data, $P$, reported in this paper are the average values obtained on three samples. The uncertainty on $P$ value was better than $3 \%$. The relative permeability values were calculated for each gas from $P$ data and the precision on this parameter was then better than $6 \%$.

\subsection{Preparation of Poly(E-caprolactone)/Clay Masterbatches.} Poly( $\varepsilon$-caprolactone) (PCL) has been grafted on the organoclay surface by ring-opening polymerization of $\varepsilon$ caprolactone (CL) in the presence of $\mathrm{Sn}(\mathrm{Oct})_{2}$ according to a "coordination-insertion" mechanism, as reported in literature [13].

Before polymerization, the organomodified montmorillonite (CL30B) $(4.73 \mathrm{~g})$ was dried in vacuum $\left(10^{-2} \mathrm{~mm} \mathrm{Hg}\right)$ at $70^{\circ} \mathrm{C}$ overnight in a glass reactor equipped with a magnetic stirrer. A toluene solution of $\mathrm{Sn}(\mathrm{Oct})_{2}\left(6 \mathrm{~mL}, 3.010^{-4} \mathrm{~mol}\right)$ was then added to the clay under nitrogen flow. A given amount of $\varepsilon$-caprolactone $(10 \mathrm{~mL}, 0.09 \mathrm{~mol})$ was finally added such that the $[\text { monomer }]_{0} /[\mathrm{Sn}]_{0}$ molar ratio was 300 . The polymerization was carried out at $100^{\circ} \mathrm{C}$ for 7 days and stopped by temperature quenching. The polyester produced was dissolved in toluene and precipitated in heptane. The precipitate was dried in vacuum at room temperature. A monomer conversion of $90 \mathrm{wt} \%$ was determined, yielding grafted PCL chains with an $M_{n}$ estimated at ca. 1500 g.mol ${ }^{-1}$, based on previously reported data [13].

The clay content in the so-produced PCL-grafted CL30B nanohybrid was checked by TGA (Q 50 from TA Instruments, $20^{\circ} \mathrm{C} / \mathrm{min}$ under helium) giving an inorganic content of $23.7 \mathrm{wt} \%$. The investigated masterbatches are coded as follows: CL30B-PCL for the grafted-PCL masterbatch.

2.4. Preparation of Nanocomposites. Previous studies have shown $[28,29]$ the possible degradation of PCL in the presence of catalytic residues. In order to avoid any unde- sirable parallel effect, Irganox MD1024 (0.05 wt\%), a metal deactivator, was blended with SAN using a Brabender internal mixer operating at $220^{\circ} \mathrm{C}$ for 5 minutes with a rotation speed of $60 \mathrm{rpm}$. For the sake of simplicity, the SAN/Irganox MD1024 blend is just noted SAN.

SAN/layered silicate composites were prepared by melt blending SAN and the PCL-based masterbatches using a Brabender internal mixer operating at $165^{\circ} \mathrm{C}$ for 10 minutes with a rotation speed of $75 \mathrm{rpm}$. The collected samples were compression molded into $3 \mathrm{~mm}$-thick plates for 150 seconds at $165^{\circ} \mathrm{C}$ under a pressure of $150 \mathrm{MPa}$ and then rapidly cooled to room temperature.

The dispersions of the PCL-based masterbatches were carried out to produce nanocomposites containing $3 \mathrm{wt} \%$ of inorganics and $8.4 \mathrm{wt} \%$ of PCL in the presence of $0.05 \mathrm{wt} \%$ of Irganox MD1024. The miscibility between the amorphous phases of SAN and PCL-grafted within SAN/CAPA2402 and SAN/CL30B-PCL systems were evidenced by only one intermediate Tg by DSC analysis (not shown here).

Direct clay dispersions, SAN/CL30B with $3 \mathrm{wt} \%$ of inorganics, and binary blends, SAN/CAPA 2402, with $8.4 \mathrm{wt} \%$ of PCL (in the presence of $0.05 \mathrm{wt} \%$ of Irganox MD1024) have also been studied, for the sake of comparison.

\section{Results and Discussion}

To carry out this study, several samples have been prepared by melt blending according to the procedure reported in the experimental part. Their compositions are gathered in Table 1.

\subsection{Materials Morphology}

3.1.1. WAXD and AFM Characterization of Nanocomposites. The WAXD patterns of the SAN nanocomposites with $3 \mathrm{wt} \%$ of clay (SAN/CL30B and SAN/CL30B-PCL) are presented in Figure 1. Both patterns present first- and second-order peaks related to the separation of the clay layers, indicating that clay organization as repetitive multilayer is preserved in the nanocomposites. The clay interlayer distance increased from $d_{001}=1.84 \mathrm{~nm}\left(2 \theta=4.7^{\circ}\right)$ in the neat organoclay (CL30B) to $d_{001}=3.2 \mathrm{~nm}\left(2 \theta=2.65^{\circ}\right)$ and $d_{001}=3.6 \mathrm{~nm}(2 \theta=$ $2.41^{\circ}$ ) in the SAN/CL30B and SAN/CL30B-PCL nanocomposites, respectively. The increase of the clay interlayer $d$ spacing is due to the intercalation of the polymer chains and leads to a shift of the diffraction peak toward lower angle values, according to Bragg's law $(n \lambda=2 d \sin \theta$, where $n$ is an integer determined by the order given, $\lambda$ is the wavelength of X-rays, $d$ is the spacing between the planes in the atomic lattice, and $\theta$ is the angle between the incident ray and the scattering planes) [1]. $d_{002}$ diffraction order for SAN/CL30B and the SAN/CL30B-PCL are also detected at $2 \theta=5.5^{\circ}$ and $2 \theta=4.7^{\circ}$. In addition to intercalation, exfoliation could also occur in these nanocomposites. However, the delamination of the platelets and their dispersion in the polymer matrix leads to a loss of the diffraction signal. To overcome that problem, and investigate the size and spatial distribution of the intercalated clay aggregates, XRD measurements are complemented with AFM analyses. 
TABLE 1: Description of the studied materials.

\begin{tabular}{lcc}
\hline Materials & Compatibilizer & Organoclay \\
\hline SAN $^{[\mathrm{a}]}$ & - & - \\
$\mathrm{SAN}^{[\mathrm{a}]} / \mathrm{CL} 30 \mathrm{~B}$ & - & CL30B (3 wt $\%$ of inorganics $)$ \\
$\mathrm{SAN}^{[\mathrm{a}]} /$ CAPA 2402 & CAPA 2402 $(8.4 \mathrm{wt} \%$ of PCL $)$ & - \\
SAN $^{[\mathrm{a}]} /$ CL30B-PCL & Grafted PCL $(8.4 \mathrm{wt} \%$ of PCL $)$ & CL30B (3 wt $\%$ of inorganics) \\
\hline
\end{tabular}

${ }^{[a]}$ Irganox MD1024 (0.05 wt\%), a metal deactivator, was blended with SAN. The SAN/Irganox MD1024 blend is just noted SAN.

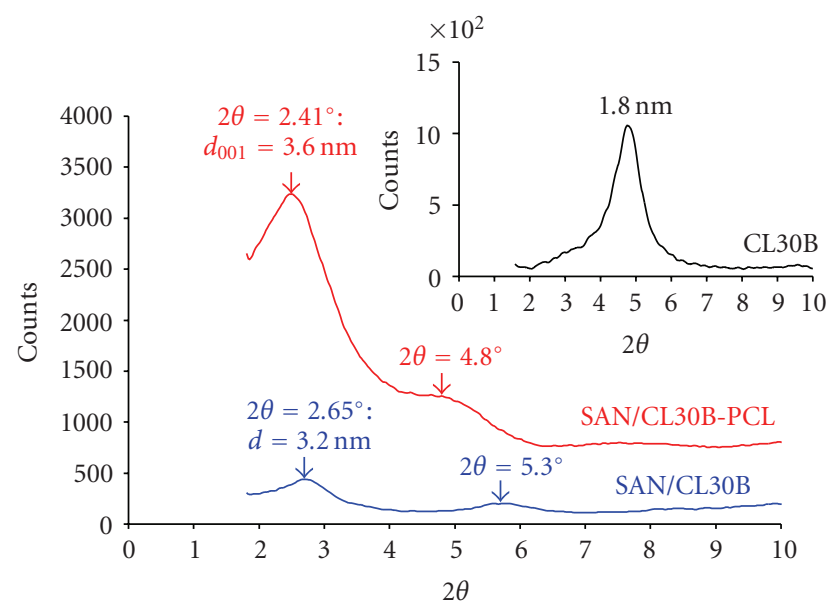

FIGURE 1: WAXD patterns of SAN/CL30B and SAN/CL30B-PCL with $3 \mathrm{wt} \%$ of inorganics. The inset shows the pattern for the pristine CL30B.

The first image (Figure 2(a)) shows a composite obtained with the direct blend (SAN/CL30B). Large aggregates of clay that can have dimensions up to a few microns are surrounded by a few isolated platelets, or small stacks/aggregates, that appear as thin black lines (the clay platelets are orthogonal to the sample surface). Despite their dimensions, the large clay aggregates are intercalated, as deducted from WAXD (the peak corresponding to nonintercalated neat CL30B has completely disappeared). Both the size of the large aggregates and the small density of isolated platelets when compared to better dispersed systems suggest that the SAN intercalation did not allow the real destructuration of the silicate aggregates; the composite has globally the morphology of a microcomposite rather than that of a nanocomposite. The second image (Figure 2(b)) shows on the same scale a composite obtained with the PCL-grafted organomodified clay masterbatch (SAN/CL30B-PCL). A much better dispersion of clay is observed, with only isolated platelets and small aggregates visible (again as black lines). These results are characteristics of a semi-intercalated, semiexfoliated structure.

The most important conclusion here is that the PCL-clay nanohybrid masterbatch technique allows obtaining a more homogeneous and better dispersion of clay throughout the SAN matrix.

3.1.2. NMR Spectroscopy Characterization of Nanocomposites. A complementary method developed at NIST [9] has also been used to quantify the degree of nanodispersion of the layered silicate in the SAN matrix. This method, based on solid state nuclear magnetic resonance (NMR) of protons, uses the direct influence of the paramagnetic $\mathrm{Fe}^{3+}$ ions embedded in the aluminosilicate layers of the MMT, on polymer protons within about $1 \mathrm{~nm}$ from clay platelet surface. The presence of silicate creates "relaxation sources" which, via spin diffusion, significantly shorten the overall $\mathrm{T}_{1}{ }^{\mathrm{H}}$ (proton longitudinal relaxation time). We used $\mathrm{T}_{1}{ }^{\mathrm{H}}$ as an indicator of the nanodispersion of the clay and spin diffusion modeling was used to describe this phenomenon and to quantify the degree of nanodispersion. The main expectation is that, for a given overall clay concentration, the better the dispersion of single MMT layers is, the shorter the average $\mathrm{T}_{1}{ }^{\mathrm{H}}$ is. $\mathrm{T}_{1}{ }^{\mathrm{H}}$ measurements can, therefore, be used to probe the dispersion at the nanoscale of MMT in the polymer. This approach, which was fully described in a previous paper [9], thus allows determining the degree of nanodispersion represented herewith by the parameter $f$. This parameter is actually normalized to 1 , meaning that a nanocomposition displaying an $f$ value equal or close to 1 can be considered as fully exfoliated. $f$ represents the fraction of polymer/clay interface effectively formed with respect to the maximum amount of polymer chains that could fit around individual nanoplatelets [9]. From Table 2, we can observe that $\mathrm{T}_{11} \mathrm{H}$, the long components of proton longitudinal relaxation times, are significantly shortened in the composites with respect to the SAN matrix, as expected due to the paramagnetically induced relaxation at the polymer-clay interface [10]. But the interesting result concerns the dramatic decrease of $\mathrm{T}_{11} \mathrm{H}$, for the same clay content, in the SAN/CL30B-PCL (3.12 seconds) system with regard to the SAN/CL30B blend (21.75 seconds). Interestingly, the SAN/CL30B-PCL system exhibits an $f$ value of 1 whereas the $f$ value of the direct blend is only 0.23 . So, in agreement with previous observations by AFM and WAXD, NMR results fully confirm that the use of the PCL/clay nanohybrid masterbatch technique leads to a significant improvement of the organoclay nanodispersion in the SAN matrix.

These observations are of key importance to understand the properties and the effect of clay exfoliation reported hereafter.

3.1.3. Thermal Properties of Nanocomposites. As a first step, the effects of nanoclay dispersion on both thermal and oxygen barrier properties can be studied, qualitatively, via thermogravimetric analysis. 


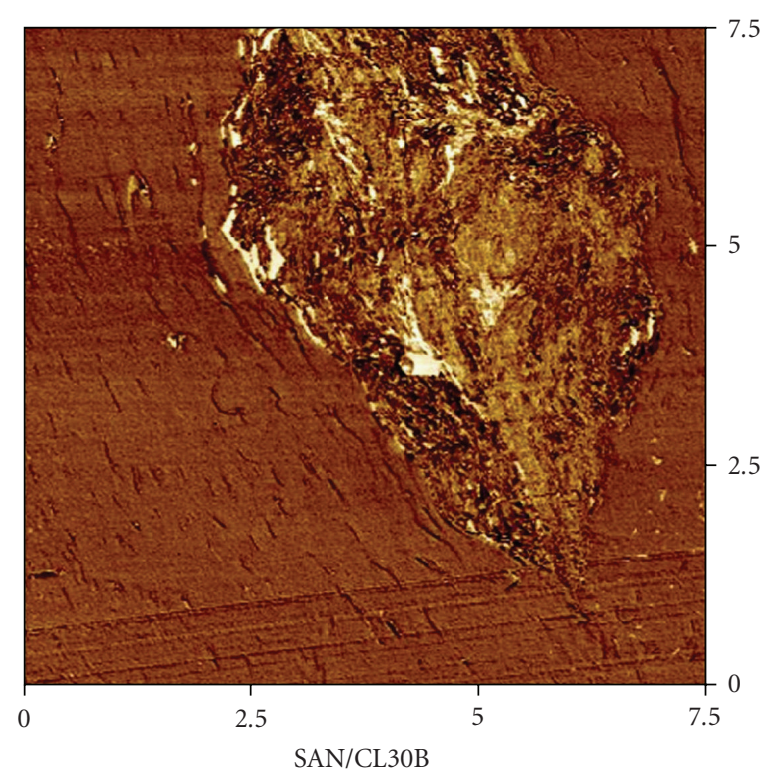

(a)

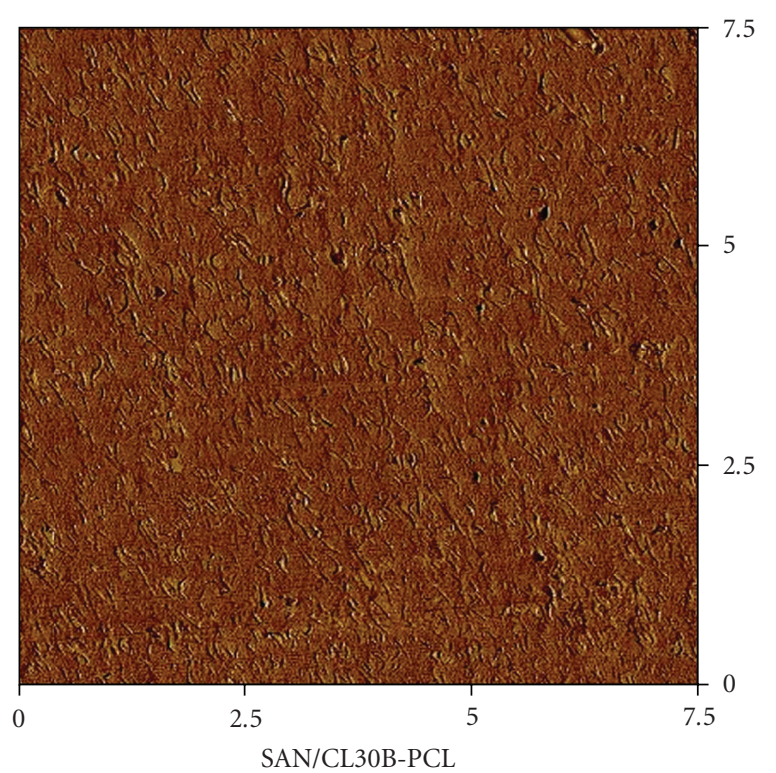

(b)

FIGURE 2: TMAFM phase image of SAN/CL30B and SAN/CL30B-PCL with $3 \mathrm{wt} \%$ of inorganics. A clay aggregate $\sim 10 \mu \mathrm{m}$ long is seen in the left image. Isolated platelets and small aggregates are only visible when orthogonal to the sample surface; they are seen as thin dark lines.

TABle 2: $\mathrm{T}_{11}{ }^{\mathrm{H}}$ relaxation time and $f$ parameter, that is, the fraction of polymer/clay interface effectively formed with respect to the maximum amount of polymer chains that could fit around individual nanoplatelets, for SAN/CL30B and SAN/CL30B-PCL with $3 \mathrm{wt} \%$ of inorganics.

\begin{tabular}{lcc}
\hline & $\mathrm{T}_{11}{ }^{\mathrm{H}}(\mathrm{s})$ & $f$ \\
\hline SAN & 41.7 & - \\
SAN/CL30B & 21.71 & 0.23 \\
SAN/CL30B-PCL & 3.12 & 1 \\
\hline
\end{tabular}

So, the thermal degradation behavior of SAN, SAN/ CAPA 2402, SAN/CL30B, and SAN/CL30B-PCL nanocomposites has been studied by thermogravimetric analysis with a heating rate of $20^{\circ} \mathrm{C} / \mathrm{min}$ under air or helium flow. Figure 3 shows the thermogravimetric (TGA) curves and the first derivative thermogravimetric curves (DTG) under air flow. Firstly, the maximum of the DTG curves were chosen to compare the thermal behavior of the nanocomposites in air. Secondly, Table 3 compares the DTG maximum values in air and in helium in order to highlight the so-called "nanoeffect" on thermal properties [7]. The "nanoeffect" is explained by well dispersed clay layers, which hinder diffusion of volatile decomposition products as well as oxygen penetration owing to the increase of tortuous pathway.

The complete thermal degradation behavior of SAN and SAN/CL30B has been investigated by Jang and Wilkie [8]. Thermodegradation and thermooxidation of SAN take place in one stage. Whatever the gas flux, the degradation pathway of SAN follows the same degradation pathway, as described for polystyrene: chain scission followed by $\beta$-scission (depolymerization). However, in air, the chain oxidation leads to degradation at lower temperatures. The maximum of DTG is located at $435^{\circ} \mathrm{C}$ in helium versus $417^{\circ} \mathrm{C}$ in air (see Table 3 ). In the presence of clay, only radical recombination and extensive random scission are observed [8].

The possible influence of PCL in the degradative pathway has been first investigated for the SAN/CAPA 2402 blend. The degradation pathway of PCL has been proposed by Stretz et al. [24]. The thermodegradation of PCL takes place in two stages. The first process implies a statistical rupture of the polyester chains via ester pyrolysis reaction; for example, with CAPA 2402, the maximum of DTG is detected close to $360^{\circ} \mathrm{C}$ (in air, $20^{\circ} \mathrm{C} / \mathrm{min}$ ). The second step leads to the formation of $\varepsilon$-caprolactone (cyclic monomer) as a result of an unzipping depolymerization process; for example, with CAPA 2402, the maximum of DTG is detected close to $410^{\circ} \mathrm{C}$ (in air, $20^{\circ} \mathrm{C} / \mathrm{min}$ ). In the case of the SAN(91.6\%)/PCL(8.4\%) blend, the DTG curve of Figure 3 shows only one degradation step, with a maximum at $423^{\circ} \mathrm{C}$ in air. This result could be linked to a possible increase of radical recombination between cleaved chains of SAN and PCL, which leads to a delay for the weight loss.

In the case of the direct blend of SAN with the organoclay (SAN/CL30B), the maximum of DTG is recorded at $425^{\circ} \mathrm{C}$ in air (Figure 3). This result is similar to those obtained by Jang and Wilkie [8] and Chu et al. [19] for equivalent composite structures. Furthermore the comparison between the degradation temperature in air and in helium (Table 3 ) shows that this short delay of weight loss, which derives from the barrier effect due to diffusion of both the volatile thermooxidation products to the gas phase and oxygen from the gas phase to the polymer [7] (thus the "nanoeffect"), is 


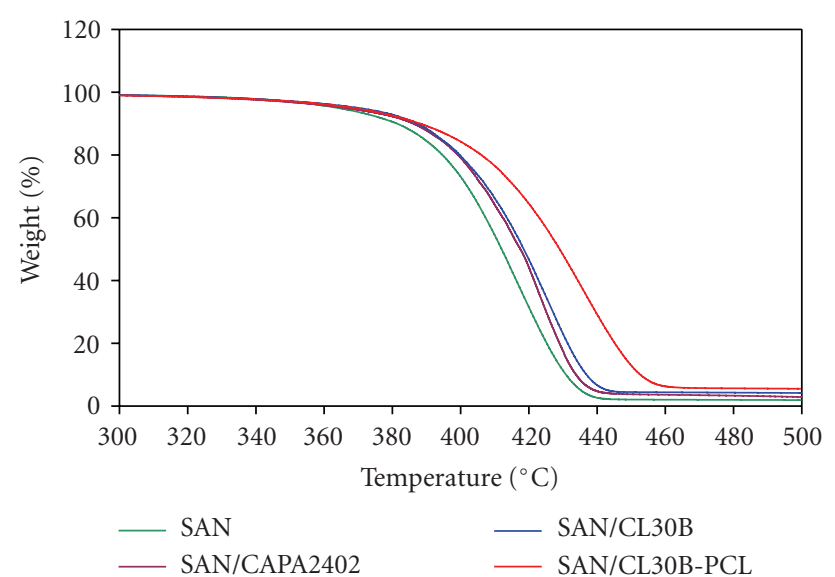

(a)

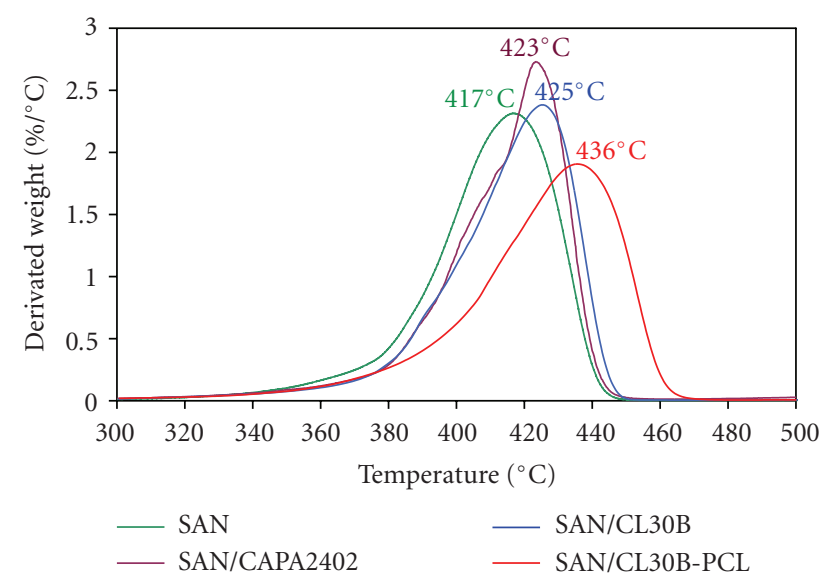

(b)

FIGURE 3: Thermogravimetric analysis curves of SAN, SAN/CAPA 2402, SAN/CL30B and SAN/CL30B-PCL with $3 \mathrm{wt} \%$ of inorganics in air, at $20^{\circ} \mathrm{C} / \mathrm{min}$.

TABLE 3: Values of the maximum derivated weight loss peaks obtained from thermogravimetric analysis (DTG) in air and in helium, at $20^{\circ} \mathrm{C} / \mathrm{min}$.

\begin{tabular}{lcc}
\hline & $\begin{array}{c}\text { Maximum } \\
\text { derivated weight } \\
\text { loss peakin air }\left({ }^{\circ} \mathrm{C}\right)\end{array}$ & $\begin{array}{c}\text { Maximum } \\
\text { derivated weight } \\
\text { loss peak in helium } \\
\left({ }^{\circ} \mathrm{C}\right)\end{array}$ \\
\hline SAN & 417 & 435 \\
SAN/CAPA 2402 & 423 & 436 \\
SAN/CL30B & 425 & 437 \\
SAN/CL30B-PCL & 436 & 441 \\
\hline
\end{tabular}

not optimum because of a structure where the clay sheets are poorly dispersed.

In clear contrast, the use of the PCL/clay nanohybrid masterbatch with the SAN/CL30B-PCL blend leads to a longer delay of weight loss in air (Figure 3). The maximum of DTG is increased by $+8^{\circ} \mathrm{C}$ between SAN and SAN/CL30B with respect to $+19^{\circ} \mathrm{C}$ between SAN and
SAN/Cl30B-PCL. But the most interesting result concerns the comparison between the degradation in air and in helium with both SAN and SAN/CL30B-PCL. Indeed, Table 3 and Figure 4 compare the maximum of the DTG curves and the degradation behavior of SAN and SAN/CL30B-PCL in air and in helium. Contrary to SAN or SAN/CL30B, the degradation behavior of SAN/CL30B-PCL is almost similar in air and in helium. This result is a characteristic of a "nanoeffect" induced by well dispersed clay nanoplatelets. Indeed, this well dispersed clay layers hinder diffusion of volatile decomposition products as well as oxygen penetration thanks to the increase of tortuous pathway, for a very low amount $(3 \mathrm{wt} \%)$ of inorganic nanoplatelets. This phenomenon is only obtained with nanofillers of high shape factor $[1,7]$ and the same effect, with micron-sized fillers, would require much larger amount of microparticles.

So, the very well dispersed clay nanocomposite obtained with a PCL/clay nanohybrid masterbatch leads to significantly improved thermal degradation performances.

These promising results allow us to suggest that other properties could be improved because of the large increase of the SAN/clay interface. Among others, the flame retardancy and the gas barrier resistance properties of SAN, SAN/CL30B, and SAN/CL30B-PCL have therefore been investigated.

3.1.4. Flame Retardancy Properties of Nanocomposites. As for the flame retardancy properties, an easy qualitative experiment consists in burning two bar specimens of SAN and SAN/CL30B-PCL at the same time and in observing how the samples burn. Figure 5 and the support information clips illustrate this first qualitative fire experiment. We followed the combustion of SAN (on the left) and the SAN/CL30BPCL nanocomposite (on the right).

Straight away, a different behavior is visible. The SAN specimen is burning faster than the nanocomposite sample with an intensive dripping (i.e., continuous formation of burning droplets). The same behavior has been observed with the direct blend (SAN/CL30B) (not shown here). After 4 minutes, the combustion of the SAN specimen is complete while SAN/CL30B-PCL is burning much more slowly without any dripping. The end of the combustion is observed only after 7 minutes, and at the end of the test, a cohesive char remains. So, this basic experiment shows the interest of the PCL-grafting masterbatch strategy for the flame resistance of SAN systems.

The flame retardant properties of SAN, SAN/CL30B, and SAN/CL30B-PCL have also been investigated by mass loss cone calorimetry. In a typical experiment, the heat release rate (HRR) developed upon materials combustion is recorded as a function of time. Indeed, the theory of polymer nanocomposite flammability predicts that mass transfer is altered by the presence of clay platelets [30]. Actually high aspect ratio $(\sim 100-700 \mathrm{~nm})$ platelets dispersed in the matrix are known to create a tortuous path for volatile pyrolysis products, reducing the rate at which such volatiles can escape the condensed phase and contribute to heat release in the burning gas phase. Furthermore 


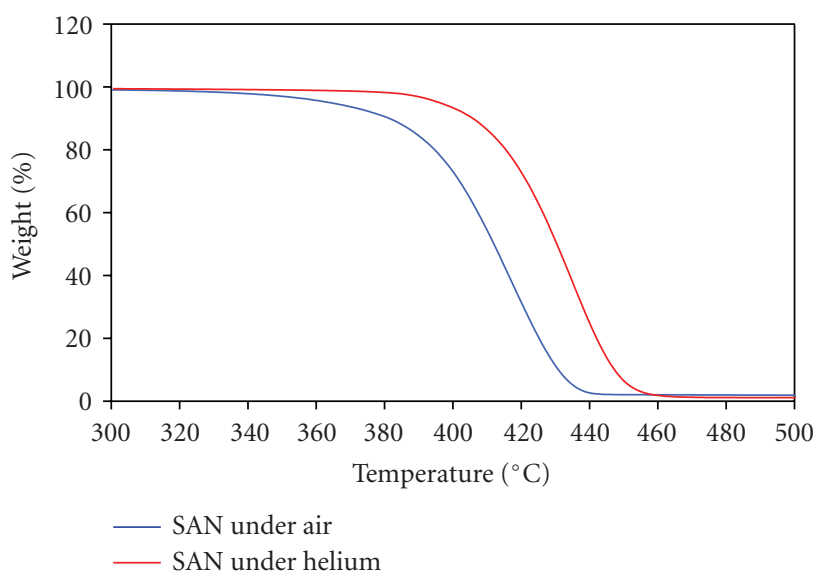

(a)

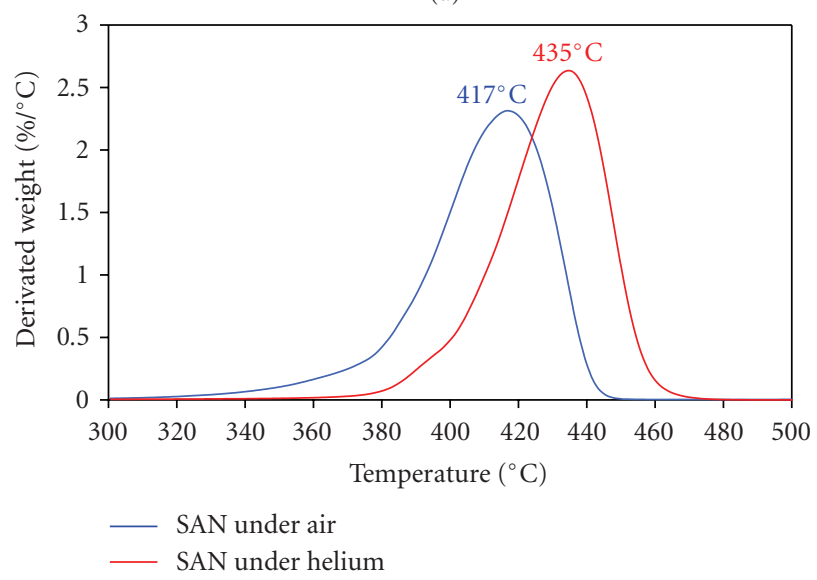

(b)

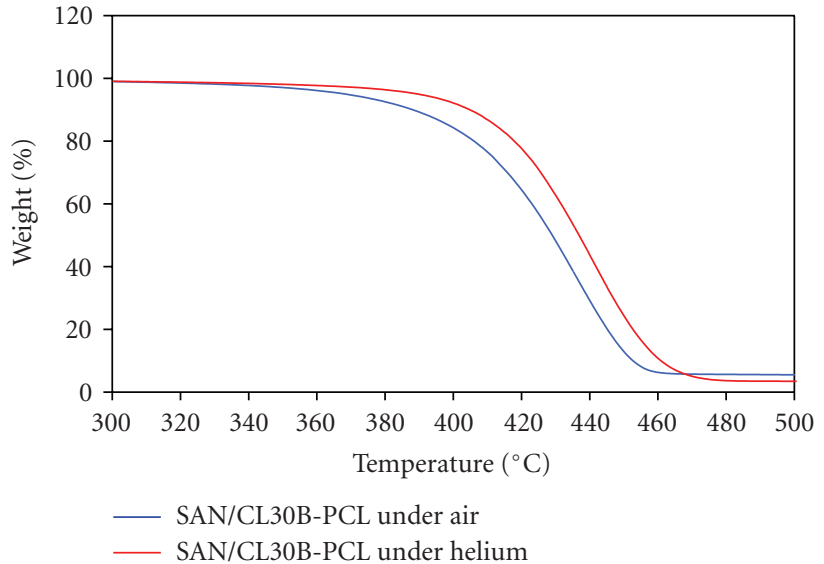

(c)

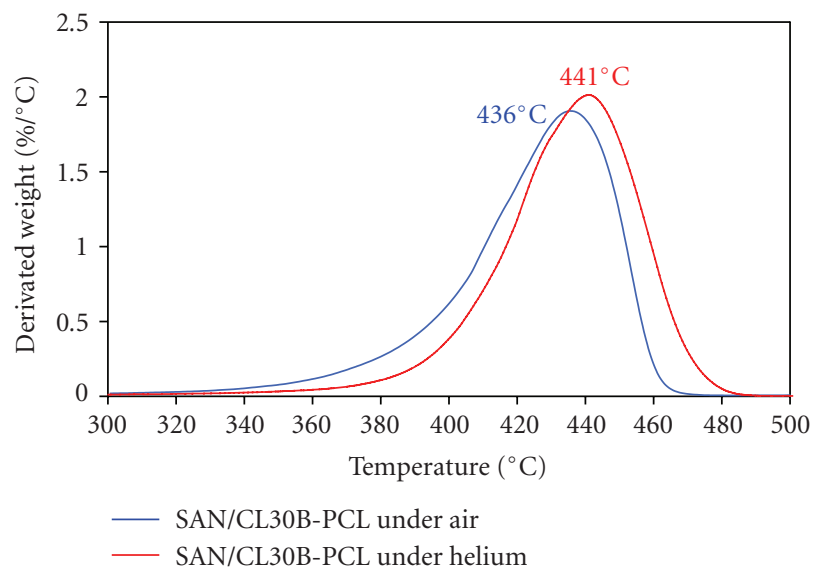

(d)

FIgURE 4: Thermogravimetric analysis curves of SAN and SAN/CL30B-PCL with $3 \mathrm{wt} \%$ of inorganics in air and in helium, at $20^{\circ} \mathrm{C} / \mathrm{min}$.

the slower diffusion of the free radical products would create a higher probability of collision and recombination (crosslinking), and the build up of a thermally insulative char layer [21] at the surface of the burning material. In Figure 6 it can be observed that the use of nanoclay leads to a reduction of the peak of heat release rate (PHRR), which is a major parameter in controlling flame propagation in fire [31]. The PHRR reduction of the direct blend (SAN/CL30B) is similar to values reported in the literature $[10,21]$ at same clay content $(\sim-22 \%)$. The most relevant result concerns larger PHRR reduction for the SAN/CL30PCL sample $(\sim-41 \%)$. Another interesting observation concerns the residues. Samples obtained after combustion are shown in Figure 7. No residue is observed for the SAN sample (Figure $7(\mathrm{a})$ ). Some residue trace is observed for the direct blend (SAN/CL30B) (Figure 7(b)) with no cohesion, as also reported by Stretz and Paul [21] while significantly larger monolithic residue, highly cohesive and homogeneous, is obtained for the SAN/CL30B-PCL nanocomposites (Figure $7(\mathrm{c})$ ). This result confirms the importance of very well dispersed nanoclay structure to enhance the fire retardancy properties.
3.1.5. Gas Transport Properties. From a gas transport point of view, nanocomposites based on amorphous matrices are often considered as a permeable continuous phase (the polymer matrix) in which impermeable nanoplatelets are dispersed (silicate layers). An extensive explanation of layered silicate/polymer gas transport theory has been given by Gain et al. [32]. Table 4 presents the permeability coefficients measured for SAN, SAN/CAPA 2402, SAN/CL30B, and SAN/CL30B-PCL nanocomposites for different gases (helium, carbon dioxide, and oxygen). The permeability coefficients recorded for the SAN matrix are similar to those given in literature [33].

As a first step, the permeability of the nanocomposites is compared with that of their respective matrix. The ratio of SAN/CL30B nanocomposite permeability on neat SAN permeability leads to a value of about 0.7 whatever the gas whereas the ratio of SAN/CL30B-PCL permeability on the respective SAN/CAPA 2402 matrix permeability is much lower. Indeed a value of 0.43 is obtained in that case for all gases. This evolution can be directly related to the clay dispersion state in each nanocomposite. As previously discussed, an enhanced organoclay nanodispersion leading 


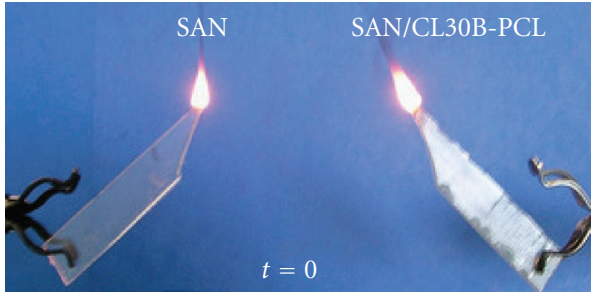

(a)

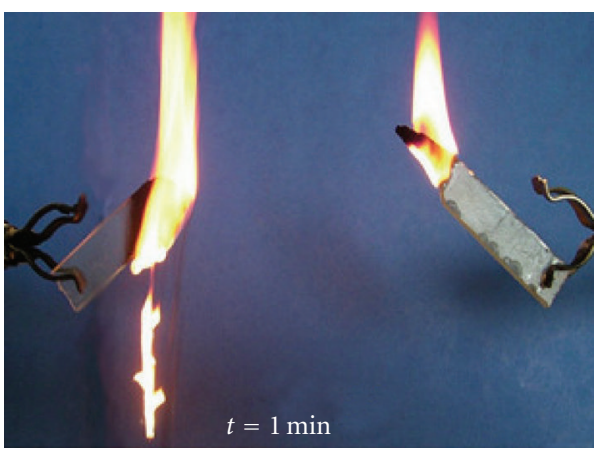

(b)

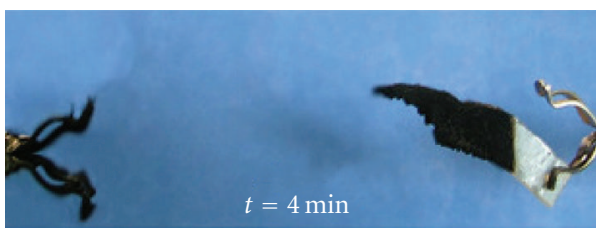

(c)

Figure 5: Qualitative flame test of SAN (on left) and SAN/CL30BPCL (on right) with $0.05 \mathrm{wt} \%$ of Irganox MD1024 and $3 \mathrm{wt} \%$ of inorganics. (Support information clips: http://mail.materianova .be/pub/supportinginformationbenalietal.wmv).

to a higher tortuosity effect is observed for SAN/CL30B-PCL in comparison with SAN/CL30B.

Before studying the evolution of SAN/CL30B-PCL nanocomposite gas transport properties with respect to neat SAN, the PCL effect on SAN gas transport properties was analyzed with the binary blend (SAN/CAPA 2402). A significant decrease of helium permeability coefficient between SAN and SAN/CAPA 2402 is noted in Table 4 whereas the carbon dioxide and oxygen permeability variations are smaller. The PCL matrix gas transport properties can explain these results. Indeed, the carbon dioxide and oxygen permeability coefficients of PCL matrix are known as particularly higher than those of unmodified SAN matrix (e.g., 13.9 barrer versus 4.43 for carbon dioxide [32] and 13 barrer versus 1.10 for oxygen [34]) while helium permeability coefficient of PCL matrix is lower than that of SAN matrix (3.1 barrer versus 14.33 barrer) [32]. So, the PCL effect on SAN gas transport depends on gas and it can be taken into account according to the additivity rule proposed for miscible systems in the following equation:

$$
\ln P=\phi_{1} \ln P_{1}+\phi_{2} \ln P_{2}
$$

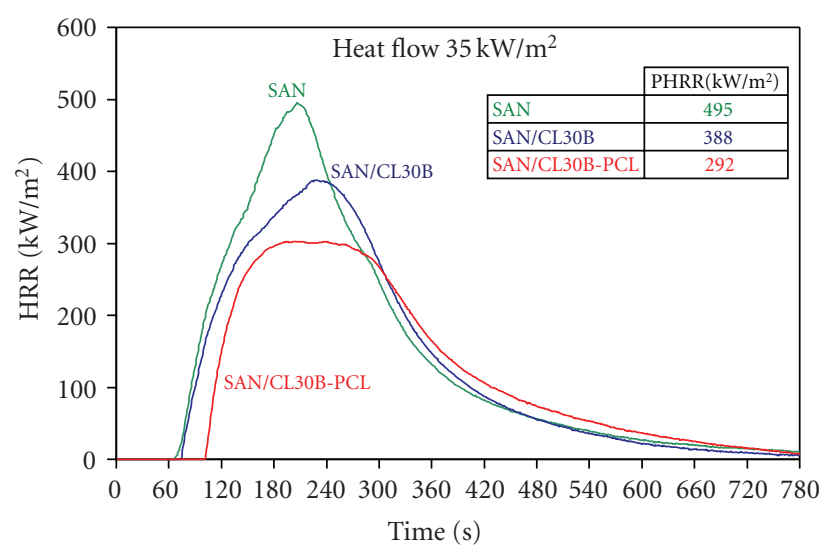

FIGURE 6: Comparison of the heat release rate (HRR) plots and peak of heat release rate (PHRR) of SAN, SAN/CL30B and SAN/CL30BPCL with $3 \mathrm{wt} \%$ of inorganics at $35 \mathrm{~kW} / \mathrm{m}^{2}$ heat flux.

TABLE 4: Gas transport properties of the films of SAN, SAN/CAPA 2402, SAN/CL30B, SAN/CL30B-PCL with $3 \mathrm{wt} \%$ of inorganics. $P$ is the permeability coefficient.

\begin{tabular}{lccc}
\hline & $P_{\mathrm{He}}($ barrer $)$ & $P_{\mathrm{CO}_{2}}$ (barrer) & $P_{\mathrm{O}_{2}}$ (barrer) \\
\hline SAN & 14.33 & 4.43 & 1.10 \\
SAN/CAPA 2402 & 10.62 & 4.15 & 1.43 \\
SAN/CL30B & 9.65 & 2.99 & 0.82 \\
SAN/CL30B-PCL & 4.74 & 1.80 & 0.62 \\
\hline
\end{tabular}

with $P$ the permeability of the blend, $P_{1}$ and $P_{2}$ the permeability coefficients of the components of the blend, and $\phi_{1}$ and $\phi_{2}$ the volume fraction of each component in the blend.

The permeability values for the blend are 10.62 barrer versus 12.60 barrer theoretical for helium, 1.43 barrer versus 1.35 barrer theoretical for $\mathrm{O}_{2}$, and 4.15 barrer versus 4.87 barrer theoretical for carbon dioxide showing a relatively good agreement between experimental and theoretical permeability values and confirming the presence of strong interactions between SAN and PCL [33, 35].

The SAN relative permeability of SAN/CAPA 2402, SAN/CL30B-PCL, and SAN/CL3OB nanocomposites is reported in Figure 8 for helium, carbon dioxide, and oxygen. In comparison with SAN/CL30B, the SAN relative permeability of SAN/CL30B-PCL nanocomposite is lower but it depends on the gas nature. This result can be analyzed taking into account two main combined effects, that is, clay dispersion degree and the presence of PCL. The higher clay exfoliation observed in SAN/CL30B-PCL in comparison with SAN/CL30B leads to a higher decrease of the permeability. Furthermore, owing to PCL, the SAN relative permeability properties of SAN/CL30B-PCL nanocomposite depend on the gas nature. So, the larger decrease of permeability coefficient is measured with helium $(\sim-67 \%)$, followed by the decrease with carbon dioxide $(\sim-59 \%)$ and with oxygen $(\sim-43 \%)$. 


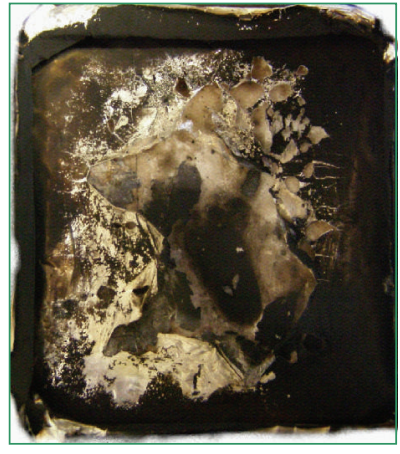

SAN

(a)

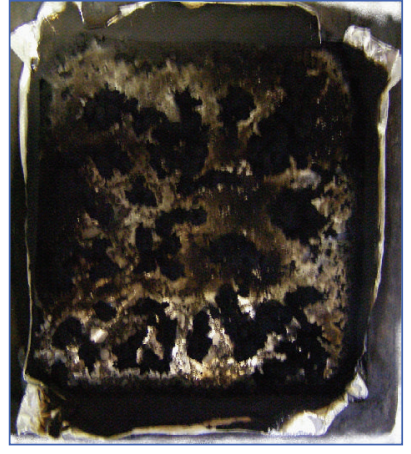

SAN/CL30B

(b)

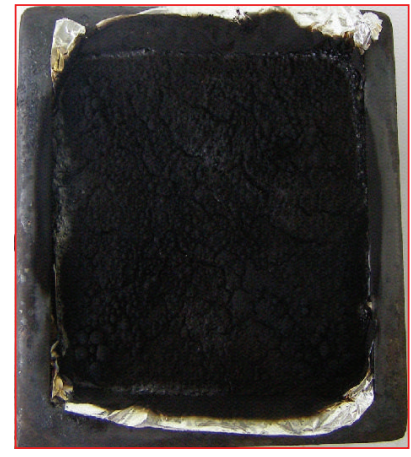

SAN/CL30B - PCL

(c)

FIGURE 7: Photographs of the char residue recovered after cone calorimetry tests of SAN, SAN/CL30B and SAN/CL30B-PCL with 3 wt $\%$ of inorganics at $35 \mathrm{~kW} / \mathrm{m}^{2}$ heat flux.

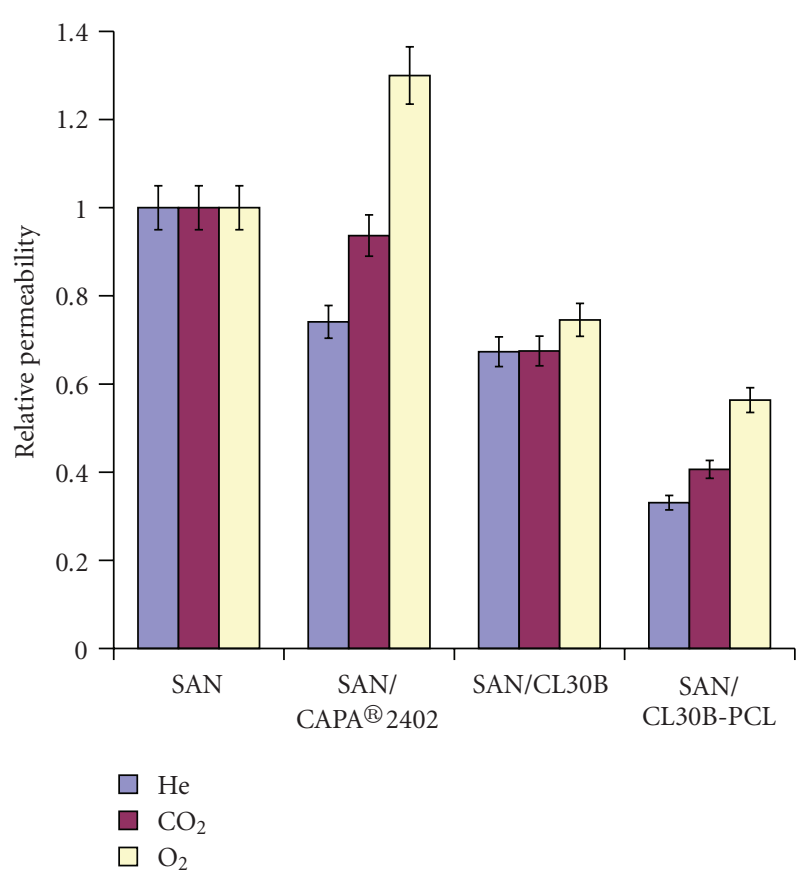

FIGURE 8: Relative gas permeability of SAN, SAN/CAPA 2402, SAN/CL30B, SAN/CL30B-PCL with $3 \mathrm{wt} \%$ of inorganics.

\section{Conclusion}

Semi-intercalated, semi-exfoliated SAN/layered silicate nanocomposites have been prepared using PCL-grafted organoclay nanohybrids as masterbatch to substantially increase the degree of exfoliation. The PCL-grafted organoclay nanohybrids are added as masterbatches in SAN by melt blending. This two-step preparation of nanocomposites leads to very well dispersed clay nanocomposites with $3 \mathrm{wt} \%$ of inorganics. Morphological (WAXD and AFM analyses) and solid state NMR spectroscopy measurements confirm a more delaminated structure in SAN nanocomposites based on PCL-clay nanohybrid masterbatch (SAN/CL30B-PCL) while only an intercalated structure is found with the direct blend (SAN/CL30B). So, a strong improvement of both fire retardancy and barrier gases resistance properties has been found with the SAN/CL30B-PCL nanocomposite, which reflects the large superiority of the PCL-clay nanohybrid masterbatches strategy over the direct blend for the SAN matrix. A decrease up to $40 \%$ of PHRR is noted with SAN/CL30B-PCL versus less than 20\% with SAN/CL30B and the permeability coefficient is widely decreased (up to $67 \%$ with SAN/CL30B-PCL versus only $30 \%$ with SAN/CL30B for helium).

As indicated in the introduction, this study is part of a larger study, which aims at developing SAN foams. So, in this specific application context it would be interesting to study more extensively the interest of PCL/clay nanohybrid masterbatches on the mechanical, flame retardancy and gas barrier properties of SAN foams.

Furthermore, the SAN matrix is considered as a model system useful [24] to understand acrylonitrile-butadienestyrene $(\mathrm{ABS})$. So, it would be interesting to extend the use of PCL/clay nanohybrid masterbatches to ABS materials. Indeed, ABS/clay systems may have several applications, including fire-retarded formulations for recyclable computer housing [24].

\section{Acknowledgments}

The authors wish to thank Professor A. Rulmont (General Chemistry and Physical Chemistry Department, University of Liège) for the WAXD analyses. S. Benali and P. Brocorens are grateful to "Région Wallonne" for a grant in the frame of the WINNOMAT program: PROCOMO. UMH and Materia Nova Asbl acknowledge the financial support from the "Région Wallonne" and the European Commission (FSE, FEDER) in the frame of objectif- 1 and phasing-out programs. This work was partially supported by the Belgian Federal Science Policy Office (PAI6/27) and by the Belgian National Fund for Scientific Research (FRS-FNRS). 


\section{References}

[1] M. Alexandre and Ph. Dubois, "Polymer-layered silicate nanocomposites: preparation, properties and uses of a new class of materials," Materials Science and Engineering $R$, vol. 28, no. 1, pp. 1-63, 2000.

[2] Y. Komori and K. Kuroda, "Layered silicate-polymer interlocation composites varieties in host materials and properties," in Polymer-Clay Nanocomposites, T. J. Pinnavaia and G. W. Beall, Eds., pp. 3-18, John Wiley \& Sons, New York, NY, USA, 2001.

[3] M. Biswas and S. S. Ray, "Recent progress in synthesis and evaluation of polymer-montmorillonite nanocomposites," Advances in Polymer Science, vol. 155, pp. 167-221, 2001.

[4] S. C. Tjong, "Structural and mechanical properties of polymer nanocomposites," Materials Science and Engineering R, vol. 53, no. 3-4, pp. 73-197, 2006.

[5] J. W. Gilman, "Flammability and thermal stability studies of polymer layered-silicate (clay) nanocomposites," Applied Clay Science, vol. 15, no. 1-2, pp. 31-49, 1999.

[6] S. Peeterbroeck, B. Lepoittevin, E. Pollet, et al., "Polymer layered silicate/carbon nanotube nanocomposites: the catalyzed polymerization approach," Polymer Engineering and Science, vol. 46, no. 8, pp. 1022-1030, 2006.

[7] M. Zanetti, G. Camino, R. Thomann, and R. Mülhaupt, "Synthesis and thermal behaviour of layered silicate-EVA nanocomposites," Polymer, vol. 42, no. 10, pp. 4501-4507, 2001.

[8] B. N. Jang and C. A. Wilkie, "The effects of clay on the thermal degradation behavior of poly(styrene-co-acrylonitirile)," Polymer, vol. 46, no. 23, pp. 9702-9713, 2005.

[9] S. Bourbigot, D. L. Vanderhart, J. W. Gilman, et al., "Investigation of nanodispersion in polystyrene-montmorillonite nanocomposites by solid-state NMR," Journal of Polymer Science Part B, vol. 41, no. 24, pp. 3188-3213, 2003.

[10] S. Bourbigot, D. L. Vanderhart, J. W. Gilman, S. Bellayer, H. Stretz, and D. R. Paul, "Solid state NMR characterization and flammability of styrene-acrylonitrile copolymer montmorillonite nanocomposite," Polymer, vol. 45, no. 22, pp. 76277638, 2004.

[11] G. Gorrasi, M. Tortora, V. Vittoria, et al., "Vapor barrier properties of polycaprolactone montmorillonite nanocomposites: effect of clay dispersion," Polymer, vol. 44, no. 8, pp. 22712279, 2003.

[12] K. Yano, A. Usuki, and A. Okada, "Synthesis and properties of polyimide-clay hybrid films," Journal of Polymer Science Part A, vol. 35, no. 11, pp. 2289-2294, 1997.

[13] B. Lepoittevin, N. Pantoustier, M. Alexandre, C. Calberg, R. Jérôme, and $\mathrm{Ph}$. Dubois, "Polyester layered silicate nanohybrids by controlled grafting polymerization," Journal of Materials Chemistry, vol. 12, no. 12, pp. 3528-3532, 2002.

[14] B. Lepoittevin, N. Pantoustier, M. Devalckenaere, et al., "Polymer/layered silicate nanocomposites by combined intercalative polymerization and melt intercalation: a masterbatch process," Polymer, vol. 44, no. 7, pp. 2033-2040, 2003.

[15] S. Benali, S. Peeterbroeck, P. Brocorens, et al., "Chlorinated polyethylene nanocomposites using PCL/clay nanohybrid masterbatches," European Polymer Journal, vol. 44, no. 6, pp. 1673-1685, 2008.

[16] P. Brocorens, S. Benali, C. Broekaert, et al., "Microscopic morphology of chlorinated polyethylene-based nanocomposites synthesized from poly(E-caprolactone)/clay masterbatches," Langmuir, vol. 24, no. 5, pp. 2072-2080, 2008.
[17] B. Lepoittevin, N. Pantoustier, M. Devalckenaere, et al., "Poly( $\varepsilon$-caprolactone)/clay nanocomposites by in-situ intercalative polymerization catalyzed by dibutyltin dimethoxide," Macromolecules, vol. 35, no. 22, pp. 8385-8390, 2002.

[18] H. A. Stretz, D. R. Paul, R. Li, H. Keskkula, and P. E. Cassidy, "Intercalation and exfoliation relationships in meltprocessed poly(styrene-co-acrylonitrile)/montmorillonite nanocomposites," Polymer, vol. 46, no. 8, pp. 2621-2637, 2005.

[19] L.-L. Chu, S. K. Anderson, J. D. Harris, M. W. Beach, and A. B. Morgan, "Styrene-acrylonitrile (SAN) layered silicate nanocomposites prepared by melt compounding," Polymer, vol. 45, no. 12, pp. 4051-4061, 2004.

[20] M. B. Ko, "Effects of acrylonitrile content on the properties of clay-dispersed poly(styrene-co-acrylonitrile) copolymer nanocomposite," Polymer Bulletin, vol. 45, no. 2, pp. 183-190, 2000.

[21] H. A. Stretz and D. R. Paul, "Properties and morphology of nanocomposites based on styrenic polymers-part I: styreneacrylonitrile copolymers," Polymer, vol. 47, no. 24, pp. 81238136, 2006.

[22] S. W. Kim, W. H. Jo, M. S. Lee, M. B. Ko, and J. Y. Jho, "Preparation of clay-dispersed poly(styrene-co-acrylonitrile) nanocomposites using poly( $\varepsilon$-caprolactone) as a compatibilizer," Polymer, vol. 42, no. 24, pp. 9837-9842, 2001.

[23] A. Kiersnowski and J. Pigłowski, "Polymer-layered silicate nanocomposites based on poly(E-caprolactone)," European Polymer Journal, vol. 40, no. 6, pp. 1199-1207, 2004.

[24] H. A. Stretz, D. R. Paul, and P. E. Cassidy, "Poly(styrene-coacrylonitrile)/montmorillonite organoclay mixtures: a model system for ABS nanocomposites," Polymer, vol. 46, no. 11, pp. 3818-3830, 2005.

[25] A. Grand, "Heat release calorimetry evaluation of fire retardant polymer systems," in Proceedings of the 42nd International SAMPE Symposium and Exhibition, vol. 5, Anaheim, Calif, USA, May 1997.

[26] M. J. Scudmore, P. J. Briggs, and F. H. Prager, "Cone calorimetry-a review of tests carried out on plastics for the association of plastic manufacturers in Europe," Fire and Materials, vol. 15, no. 2, pp. 65-84, 1991.

[27] V. Babrauskas, "Development of cone calorimeter-a bench scale rate of heat release based on oxygen consumption," NBSIR 82-2611, National Bureau of Standards, Gaithersburg, Md, USA, 1982.

[28] O. Persenaire, M. Alexandre, Ph. Degée, and Ph. Dubois, "Mechanisms and kinetics of thermal degradation of poly $(\varepsilon$ caprolactone)," Biomacromolecules, vol. 2, no. 1, pp. 288-294, 2001.

[29] H. Abe, N. Takahshi, K. J. Kim, M. Mochizuki, and Y. Doi, "Effects of residual zinc compounds and chain-end structure on thermal degradation of poly( $\varepsilon$-caprolactone)," Biomacromolecules, vol. 5, no. 4, pp. 1480-1488, 2004.

[30] J. W. Gilman, C. L. Jackson, A. B. Morgan, et al., "Flammability properties of polymer-layered-silicate nanocomposites. Polypropylene and polystyrene nanocomposites," Chemistry of Materials, vol. 12, no. 7, pp. 1866-1873, 2000.

[31] G. Camino, G. Tartaglione, A. Frache, C. Manferti, and G. Costa, "Thermal and combustion behaviour of layered silicate-epoxy nanocomposites," Polymer Degradation and Stability, vol. 90, no. 2, pp. 354-362, 2005.

[32] O. Gain, E. Espuche, E. Pollet, M. Alexandre, and Ph. Dubois, "Gas barrier properties of $\operatorname{poly}(\varepsilon$-caprolactone $) /$ clay 
nanocomposites: influence of the morphology and polymer/clay interactions," Journal of Polymer Science Part B, vol. 43, no. 2, pp. 205-214, 2005.

[33] J. S. Chiou and D. R. Paul, "Gas permeation in miscible homopolymer-copolymer blends. I. Poly(methyl methacrylate) and styrene/acrylonitrile copolymers," Journal of Applied Polymer Science, vol. 34, no. 3, pp. 1037-1056, 1987.

[34] S. Wang, H. Nishide, and E. Tsuchida, "Oxygen permeability of biodegradable copolycaprolactones," Polymers for Advanced Technologies, vol. 10, no. 5, pp. 282-286, 1999.

[35] J. S. Chiou and D. R. Paul, "Gas permeation in miscible homopolymer-copolymer blends: II. Tetramethyl bisphenol-A polycarbonate and a styrene/acrylonitrile copolymer," Journal of Applied Polymer Science, vol. 34, no. 4, pp. 1503-1520, 1987. 

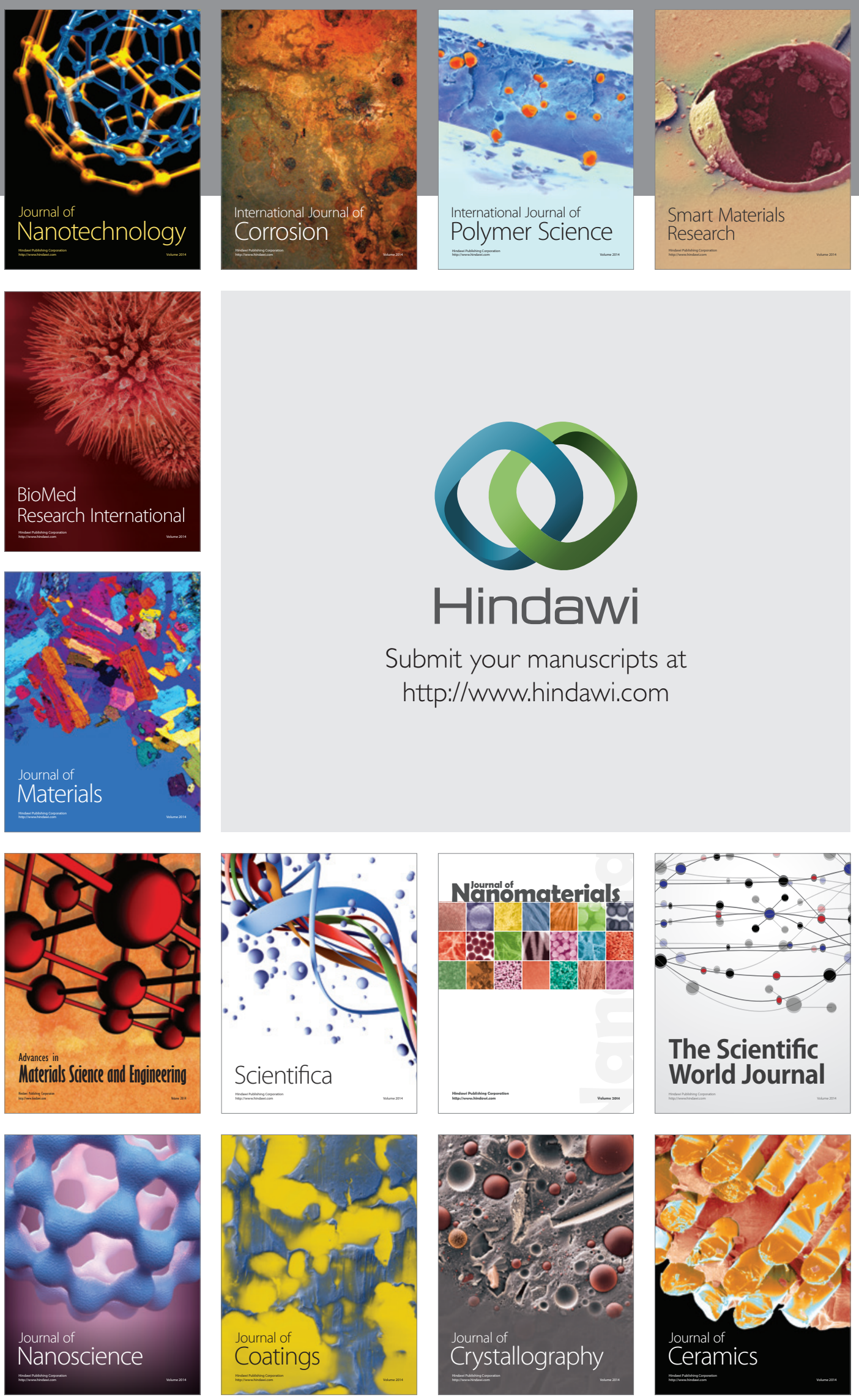

The Scientific World Journal

Submit your manuscripts at

http://www.hindawi.com

\section{World Journal}

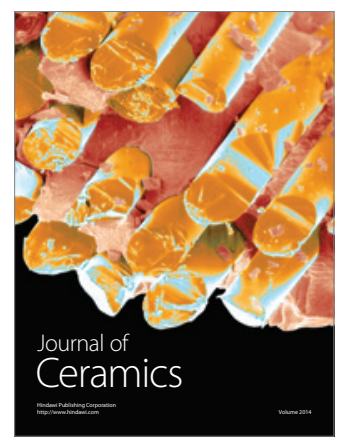

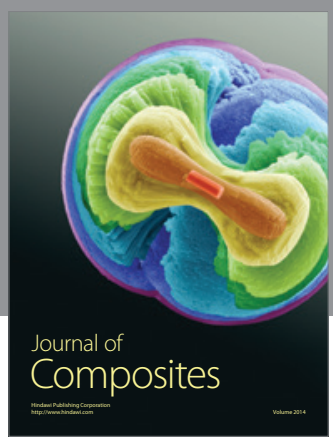
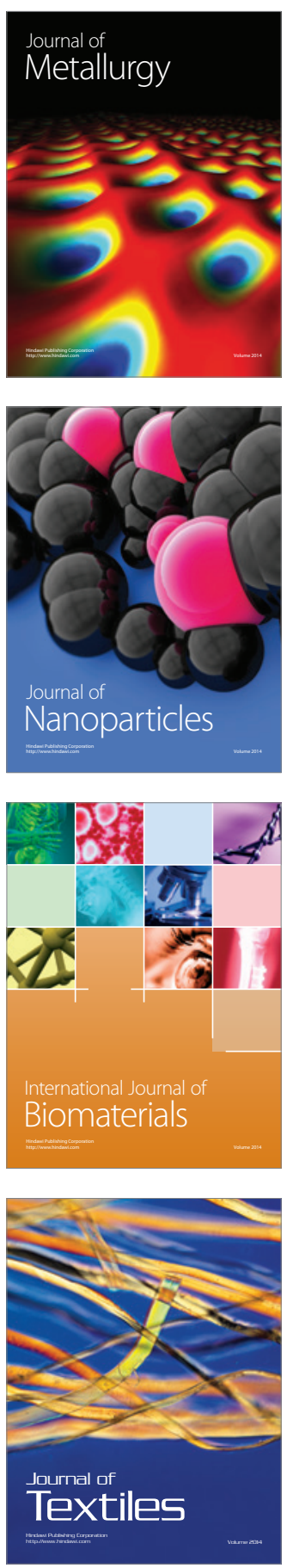